\title{
OASIS: The development of a school information system
}

\section{Graham Pegler}

\begin{abstract}
The direction and approaches adopted in the provision of school information systems have been discussed in a previous paper. The nature of the school organisation was said to lead to a unique set of difficulties in relation to the development and implementation of a school information system that could provide an integrated solution for schools; one that could satisfy the potential and scope envisaged and overcome the problems or pitfalls that exist. This paper seeks to critically examine the development of OASIS (Office Administration and School Information System) which was undertaken by the NSW Department of School Education. The reasons for the decisions made to develop an information system that would be implemented in all NSW Public Schools are instructive for others looking down the same path. The examination produces a number of observations and insights that have application to the development of school information systems.
\end{abstract}

\section{Computerised school administration in NSW public schools}

The growth model provided by Nolan (McNurlin \& Sprague, 1989, p97) of the EDP function within an organisation can be applied to the use of computers within schools. Computers have been used in schools for some years now, for teaching and for administration, however the activities of one were not, in the past, directly linked to the other by the computer technology available. As Hedberg and Harper (1992) indicate there has been little integration, despite the passage of time, even with regard to equipment, of these areas. 
To focus on the use of computers for school administration; initial efforts were generally inefficient and ineffective as they were employed for "oneoff", independent applications, the individual efforts of teachers were directed towards improving their personal position with the "new technology" and not with a concern for a wider view. In the context of the development and growth of the EDP function within an organisation, this would not be unexpected. The proliferation and experimentation with the technology are a necessary part of coming to terms with it and understanding and realising its capabilities. The efforts of executive or administrative staff of schools to improve their management activities through databases, word processors, and spreadsheets were varied as attempts were made by them to address the problems they faced as individuals within the organisation. Attendance, scheduling, anticipated enrolment models, academic reporting, class lists, class mark books, equipment maintenance and stocktaking representing just a few of the tasks to which staff devoted time to developing as computer-based activities. Consequently, many of these efforts while worthwhile for the individual were piecemeal in terms of the organisation, with consequent problems for integration and management of efforts.

The problems associated with the burgeoning use of computer hardware and software for school administration were recognised by officers of the NSW Department of School Education. The next stage of the growth model discussed by McNurlin and Sprague (1989, p.97), control, appears largely to have developed, in terms of school administration in NSW, as a result of the influence of the governing body; the NSW Department of School Education, and not from the recognition at the school level of the need for such control. However, the officers responsible generally had considerable experience in schools with computerised administration.

The concern for exercising control in the development of computerised school administration has been a major factor leading to the investigation and eventual development of a school information system for NSW schools. The "Report on the Administrative Computing Needs of Schools" (Hartley, 1986) was a relatively early indicator of this realisation. It presented issues for consideration and implications for senior management in the Department for the exercise of control. The report stated that there was a need to coordinate, control and provide leadership and guidance to schools embarking on the process of computerising school administration, as well as a necessity to ensure that the systems used would satisfy the information requirements of the Department and other Government bodies that had statutory requirements of schools.

The Department's acceptance of the aim of providing all schools with access to computing facilities for school administration required 
consequent decisions to be made by the Department on behalf of schools. Some of the important issues recognised were:

1. The introduction of computing facilities would require attention to the concerns of school personnel for the provision of support from the department and of changes to the roles of clerical personnel within the school as well as changes to the work environment required for introduction of computers. Computerised administration was recognised as being more than the provision of a program for use by schools. In this respect the Department, with the introduction of OASIS, sought agreement from the Public Service Association on work practices and technological change, and provided funds and information to the schools for the purchase of ergonomic equipment and work practices to be employed.

2. With the Department providing computing facilities for this purpose it exercised system-wide control over the approaches taken. This control extended not only to the provision of software (OASIS) for school administration but also hardware, supplied upon installation of OASIS. Through this hardware/software solution the Department was able to satisfy its requirements for the security of data, the privacy of data, the information requirements it had of schools, and work practices. In addition the uniformity of the platform upon which the system was developed was envisioned to more easily allow the development of an education system-wide network between Head Office, Regional Offices and local clusters and schools.

3. Although some schools had dedicated some resources to computerised school administration, many had not due to the limitations of staff, money and time associated with their small size. Consequently there was not the scale of the problem experienced by large organisations, described by Nolan during this stage, of integrating different (administrative) systems. Any delay however, would have made the task more difficult. A number of schools were already eagerly pursuing the computerisation of administration and library systems which were likely to be incompatible and fail to meet the information requirements of the Department. The need for direction, coordination and support was evident.

As with any systems development project, the development of a school administration system required, at this stage, a thorough analysis of the requirements of schools, as well as the requirements of the Department. In addition to conducting research in schools of the current efforts of school 
personnel, and of developments in other educational systems, trials were conducted of commercially available packages in schools, enabling the identification of features required. These trials were claimed to provide a twofold benefit: the determination of the practical requirements for implementation and secondly the development of user expertise in understanding and expressing requirements.

No one commercially available package was found to provide all the features required of an administration system suited to the needs of schools in NSW. Subsequently, the options available for the development of a school information system were analysed by the Department, leading eventually to the decision to "out-source" program development rather than develop such a system "in-house".

The detailed system specifications were developed for five modules given initial priority: School Information, Student and Staff Information, Financial Management, Library Administration and System Maintenance. The software project became known as OASIS and the successful tenderer for the software component of the project was Softlink Australia. The source code became the property of the NSW Department of School Education.

The strategy for implementation of OASIS was not simply the provision of acquired software and hardware to schools. Included in the program for installation were training courses, technological and work practice changes, including consideration of ergonomic factors, data entry assistance, manuals, security advice, privacy provisions, field testing and controlled distribution.

Following acceptance testing and field testing trials the OASIS software package was finally accepted by the Department. Installations began at the end of 1988. With the provision of hardware and software, training and support the program for its implementation has extended over a number of years and is costed at around $\$ 30,000,000$. OASIS has now been implemented in all NSW Public Schools, involving over 3000 installations (including both administration and library systems, refer next section).

\section{OASIS: The solution for NSW public schools}

OASIS has made a significant impact on the administration of schools in NSW. It has changed fundamentally the way in which the administration of many schools has been conducted by providing services that previously were not capable of being supported with the staff available, and has standardised many aspects of school administration more formally, allowing better control within the school of many of its administrative operations. Additionally it has brought many schools into the information age for the first time and advanced the progress of almost all. 
The degree of technological sophistication made available to even small schools, in terms of the integration of the information system impressed Scott. The Scott Report (1989), in a review of the workings of the Department of School Education, recommended that the implementation of the OASIS project be accelerated. Scott saw the system as not only providing technological sophistication but also as capable of assisting the thrust towards a "school centred education" approach in which schools became more autonomous in management with respect to schooling, funding and staffing.

The perspective which has been fundamental to the development of OASIS is that it has been developed on the basis of what was required, and not from what was available, the requirements having been articulated by school personnel from their experiences in schools and with school administration systems. This has been important in ensuring that the problem of the information system "tail" wagging the school management "dog" has been avoided. Evaluation of requirements extended beyond those for simple storage and retrieval of data. Concern for privacy and security of data, the relationships that exist between the stored data as a model of the important entities involved, the need to enable school personnel, who in many cases were not proficient or experienced users of computers, to manage a network, and attention to the issues beyond the provision of software and hardware for implementing such a sophisticated system are important considerations in the design and implementation of a school information system.

\section{Features of OASIS}

The OASIS system had to provide a solution for all government schools, from the smallest one teacher primary schools in the west of the state to the largest metropolitan schools. This was achieved through a combination of features:

- provision of networking capability to allow schools to expand the physical system as their requirements changed.

- modules which could be placed in operational status when schools were ready to employ them, eg, OASIS Finance.

- provision for a range of hardware to employ in different modules of the system, ie, printers, receipt printers and cash drawers, bar code wands, tape backup units.

- provision of tutorial data with which to test or experiment with data entry and reporting.

- access to support, training and advice from regions and head office.

In larger schools, separate networks are provided for the administration system and the library system. The decoupling of the library module from the administration modules, provides an additional advantage besides 
reducing the risk of breaches of privacy and security of data by students who have access to the system when utilising the inquiry function. Both systems currently have installed the same software (although operation of individual modules is controlled). This provides some measure of backup against possible corruption of programs and system files. In addition, as each operates independently of the other, if a fault occurs in one system so that it is non operational for a period of time, the other may continue to work. The data which links the two systems together is refreshed periodically by transferring from the administration system the data that the library system needs.

Comparisons of the features of the OASIS system to those developed for other educational systems are interesting. The implementation specifications developed by the Avon Local Management of Schools team U1 response to the similar directions for school-based decision making occurring in the British education system provide comfort for the directions taken here, particularly insofar as hardware and networking is concerned (Bird, 1989, p.21). Bird claims that the provision of such software will assist in the move from school administration to school management. Management decisions will be supported by the provision of programs that permit the analysis of data gathered from the supporting data processing operations and the modelling of possible alternatives.

\section{Issues and Future Directions}

The implementation of OASIS is not without its problems and can be criticised in terms of its scope and implementation by interested external parties and school personnel. However OASIS is undergoing change as a result of user requests and feedback on performance, and provides a basis for progress in this area. Some of the problems and issues are described below.

1. The hardware allocated for use in schools for OASIS is limited solely to OASIS. Third party software cannot currently be installed by schools on the existing hardware for security reasons. The School Systems unit is currently endeavouring to permit the installation of third party software, such as word processors and spreadsheets, on the fileserver without the risk of compromising the security of OASIS data. The decision to restrict all NSW Government schools to a standard solution was made on the basis that it would reduce the problems associated with implementation and support. This is of course in conflict with providing a flexible environment encouraging user experience, experimentation and innovation.

2. The provision of support to school personnel that exhibit a wide range of skills and are so widely dispersed is problematical. The 
establishment of "lighthouse" schools, regional information technology units, support "hotlines" and training courses represent the current attempts at overcoming the demands upon the staff involved in the development of OASIS in the School Systems unit. Analyses of the nature and origin of support calls are regularly conducted. Problems may require either technical or management solutions. In the initial training emphasis is given to the provision of technical knowledge, however management issues are discussed at training courses and at user meetings, principal's conferences and other such venues.

3. Security of hardware and software, corruption of data by computer viruses and privacy of data are issues that receive ongoing attention. The data is a resource that is critical to the operation of the school. Procedures for effective protection of the data have been devised, however the school staff involved are required to act on these recommended procedures. The backup and recovery routines have been changed considerably in the next version to ease the burden on school staff by increasing the level of automation and the viability of backups.

4. OASIS, in the same manner as any system development project, will continue to undergo development and change. A module for generation and maintenance of school timetables is currently being developed. Other modules are planned to support the work of career advisers, sports carnival operations, school canteens and exam scheduling. OASIS is also currently undergoing improvement to existing modules, with testing being conducted on OASIS Version 2. Changes also occur in response to the demands of the Department for information, and of schools for support. Links for split-site schools, isolated small schools and inter-library loans are also being developed as well as access to CD-ROM technology. Data export facilities are being improved to allow innovation at a school level for data use, while an improved, more intuitive, user interface should be considered for development.

5. At this stage, while OASIS provides a great deal of assistance to schools in terms of automating and standardising administrative tasks, it does not provide, or is not extensively exploited at a school level to provide, information useful to school management for forward planning. The utilisation by school principals of the information maintained by OASIS is, according to Hedberg and Harper (1992) limited, as few had 
convenient, direct access. Further development is required to enable OASIS to provide more wide-ranging decision support capabilities, and to provide guidance as to how the existing data maybe used for that purpose. Questions exist as to how well OASIS could be used to assess the effectiveness of school planning and decisions on educational outcomes.

6. The integration of the OASIS system to the instructional processes that occur in the school is another area of possible development. While OASIS can maintain information about student assessment for academic reports it does not support individual teacher maintenance of classroom assessment information for monitoring of student progress or student access in support of an instructional system. Thus OASIS does not support the instructional information system concept, and, as Hedberg and Harper (1992) point out this means that the information systems used will remain disparate, within the school and the education system. Policy (Computers in Schools, 1983) encourages this separation and so possible development of an integrated system is apparently some way off. The effectiveness of such a system, its capabilities and its potential acceptance are yet to be determined. However, OASIS can provide a useful basis for this development.

7. Management implications have not been as strongly addressed as the technical implementation. Changes in the roles of staff, the importance of the data, its capture, maintenance and ownership lead to difficulties in successfully implementing the system. Schools independently determine the roles to be performed and are responsible for management, however managerial issues and roles should be clarified with schools on implementation. School management must be involved in implementation to ensure the success of any administrative system.

8. The OASIS Project was developed utilising the SPECTRUM Project Management Methodology, however, as program development was "out-sourced" to Softlink Australia a model of the system was not fully developed or maintained. Of concern is the absence of a complete logical model for the system. Although some DFDs and ER diagrams were developed for the overall view of OASIS, and the Department does own the source code, a detailed logical model of the system is not available. It would appear that although many aspects of the system 
were developed with due regard to the requirements of users, future development and maintenance of the system could be jeopardised by this, particularly if personnel changes occur. Too much of the knowledge of the system could be lost by the departure of key staff. While Softlink remain the developers of the system, and the problems of program maintenance and development are theirs, it is not sufficient to rely upon Softlink, an outside agency, to maintain such a model (if in fact that they do), which may prove, in the long run to be an essential item for future development. It also means that it would be difficult to enable other software developers to compete with Softlink to provide further developments.

9. A more concrete strategic plan of how the OASIS system can be used to provide data linked to the Department's systems is needed to provide better direction to some aspects of its development.

Many of the problems faced reflect the need to move, or prepare for movement to the next stage of Nolan's growth model, that of mature use. As Hedberg and Harper $(1992,4)$ state this "process of attaining a 'maturity' level in information systems development requires effective planning." Control is not sufficient, further planning is needed now to ensure success of future developments.

\section{Conclusions}

The development of OASIS for school administration in NSW public schools illustrates the stage of information systems growth referred to as control and integration. Control has been imposed from above, not by school management but by Department management, which while it may cause some resentment and misunderstanding, has been necessary due to the potential proliferation of administration solutions, the general low levels of expertise and the need to ensure Departmental requirements were met. Its implementation has widened the appreciation of data management and computer technology within schools.

The development of OASIS has provided a basis for progress in provision of an integrated, instructional school information system. The foundations, built by addressing the requirements of users, and analysis of the wider organisational requirements, have contributed to the furnishing of an integrated package which goes a considerable way towards satisfying the administrative needs of schools. To extend this to provision of a complete integrated system is also likely to be beyond the resources of schools and the sophistication of school personnel alone in planning for such a system. 
Although it has relieved school personnel from the burden of planning and designing the administrative information system within the school, successful implementation depends on more than this; support from school management, delivery of suitable training and availability of support to the school are needed too. To successfully implement a school administration system depends not only upon the careful planning of its design, to ensure it meets organisational and user needs, but also upon its mode of implementation, to ensure it addresses the important sociotechnical issues that surround the introduction of technology. This study has provided some insight into the problems that school administrators and educational systems face and how OASIS has provided a solution, applicable to the NSW school system. It may also provide a means to bridge the gap between the hypothetical, totally integrated solutions for schools and the need to confront the practical technical and sociological problems to be faced.

The last stage of growth, maturity, represents that stage at which organisations can launch the next technological innovation. Maturity is reflected in planned approaches, and, as discussed, to move to this next stage will require the development of a strategic plan of the further development of OASIS and its place in the school and the Department. Contingent with this is the need to develop a logical model of the OASIS system so that the impact of change and future development can be assessed, so that vendor choice can be widened, and maintenance of the system more efficiently effected.

The lack of a comprehensive, logical model of the system that would be developed by following a specified information systems development methodology is of concern in the longer term. The absence of this model, as pointed out, could be critical in the future as the system requires maintenance and enhancement. Other issues associated with the protection of the school's data and support of school personnel in the implementation of OASIS are more immediately critical for the success of OASIS.

\section{References}

Bird, P. (1989). Countdown to Local Admin. Educational Computing, 10(1), 19-21.

Hartley, W. \& Shinta, J. (1983). Report on the Administrative Computing Needs of Schools. Unpublished, Department of School Education.

Hedberg, J. G., Harper, B. and Bloch, D. (1992). Educational information systems: Problems of the small educational organisation. Australian Journal of Educational Technology, 8(2), 132-160. http:/ / www.ascilite.org.au/ajet/ajet8/hedberg.html 
McNurlin, B. C. \& Sprague, R. H. Jr. (1989). Information Systems Management in Practice. Prentice-Hall.

NSW Department of Education (1983). Computers in Schools: A General Policy Statement.

NSW Department of School Education (1991). Computers in School Administration: OASIS Overview.

School Administration Computerisation Project (SACP) (1989). A History of Development: Information File, 15/5/89.

School Administration Unit (SAU) (1987). Important Documents File, No. 1 (1985-1986), No. 2.

Scott, B. (1989). Schools Renewal: A Strategy to Revitalise Schools Within the NSW State Education System. Management Review: NSW Education Portfolio.

Author: Graham Pegler, is currently Studying for an Honours Masters Degree in Commerce specialising in Management Information Systems where research into the application of information systems modelling and methodologies to specification of school information systems is being undertaken. He is Senior Education Officer, NSW Department of School Education, MIS Directorate, School Systems Project and was previously a high school science and computing studies teacher responsible for coordination of the school's efforts in provision and use of computer technology including the implementation of OASIS (the Department of School Education's school administration system).

Please cite as: Pegler, G. (1993). OASIS: The development of a school information system. Australian Journal of Educational Technology, 9(1), 19-29. http: / / www.ascilite.org.au/ajet/ajet9/pegler.html 